\title{
Татьяна Кузнецова Прошлое в зеркале речей Карлиса Улманиса
}

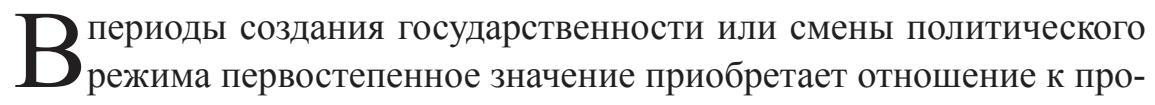
шлому, глубина которого, содержательное наполнение, качественная определенность и целостность или отсутствие таковых, способ восприятия, представление о связи с настоящим и будущим могут быть различны. Именно такая ситуация возникновения нового, позиционирующего себя по отношению к прошлому, была характерна для Латвийской Республики 1918-1940 годов, и в частности, после государственного переворота, совершенного Карлисом Улманисом в мае 1934 года. К. Улманис (1877-1942) был одним из вождей эпохи образования различных диктатур в Европе и ключевой фигурой в истории Латвии новейшего времени. Именно он стал одним из основателей и лидером ведущей политической партии в Латвийской республике (1918-1934) - Латышского крестьянского союза, созданного в апреле 1917 года; он же был избран первым главой правительства Латвии, образованного в ноябре 1918 года. Семь из девятнадцати правительств за время существования республики (с 18 ноября 1918 года и до 16 марта 1934 года) возглавлялись этим человеком. Он же совершил государственный переворот в ночь в 15 на 16 мая 1934 года, распустив парламент, политические партии и через два года наряду с должностью главы правительства заняв также пост президента страны. Его имя оказалось неразрывно связано со временем существования довоенной Латвии, став его обозначением, причем вне зависимости от оценки этого времени и лица, его персонифицирующего. Об этом 
говорят источники устной истории. Так, в рассказах о своей жизни люди, родившиеся в 20-е годы, вспоминают: «Лучше всего было при Улмане» ${ }^{1}$ или «Люди боялись той нищеты, что перенесли хотя бы во времена Ульманиса» ${ }^{2}$.

Время после переворота ознаменовалось повышенным интересом к истории латышского народа, выразившимся и в создании в 1936 году Института истории Латвии, и в насыщенности информационного пространства страны разного рода историческими материалами. Значимым структурным компонентом информационного пространства в 1930-е годы 20 века были речи политических лидеров. В Латвии - это прежде всего речи К. Улманиса, который, как было отмечено, например, в немецкой прессе 1937 года, «знает свой народ со всеми его преимуществами и недостатками, он знает, в каком месте у латышей туфли жмут, и умеет играть на их настроениях и чувствах, как на многозвучных инструментах. Но он хочет еще большего. В каждой своей речи он побуждает своих соотечественников к внутреннему единодушию, он призывает их отбросить недоверие, малодушие и пассивность, которые кроются в характере латышского народа» ${ }^{3}$. Воспитанию народа служили регулярные, почти ежедневные и по несколько раз в день, речи К. Улманиса - устные и опубликованные 4 . Его речи выходили в свет широко и разнообразно. Во-первых, публиковались отдельные речи, как, например, речь К. Улманиса, произнесенная им на открытии Первой конференции историков Балтии 16 августа 1937 года ${ }^{5}$, или машинописный вариант речи, прозвучавшей на собрании работников городских самоуправлений 24 апреля 1936 года ${ }^{6}$, или Послание народу 12 октября 1939 года, появившееся не только на латышском, но и на рус-

1 Daugavpils Universitāte Mutvārdu vēstures centrs (DU MVC), 2 - Коллекция Центра устной истории Даугавпилсского Университета.

2 Ibidem, 43 - Коллекция Центра устной истории Даугавпилсского Университета.

${ }^{3}$ Цит. по: Latvijas valsts dibinātājs un tautas vadonis Dr. Kārlis Ulmanis, Kārļa Ulmaņa 60 gadi: Svētku raksti, Rīga 1938, c. 306 (Перевод здесь и далее наш. - Т.К.).

4 По данным, приводимым Янисом Рудумсом, составителем задуманного пятитомного собрания речей и статей К. Улманиса, в 1934 году К. Улманис выступал 149 раз с разного рода речами, в 1935 году - 75 раз, в 1936 году (до 9 мая включительно) 22 paza. - Kārļa Ulmaņa runas un raksti 1934-1936, Rīga MCMXL, т. 5, c. 669-691 (Подсчитано здесь и далее нами. - Т.К.).

${ }^{5}$ K. Ulmanis, Atklāšanas runa Pirmā Baltijas vēsturnieku konferencē Rīgāa, 1937. gada 16. augustā, Rīga 1937.

${ }^{6}$ Idem, Lielā runa pilsètu pašvaldību darbinieku sanāksmē 1936. g. 24. aprīlē, [Rīga] 1936. 
ском языке 7 Во-вторых, речи К. Улманиса были неотъемлемой и превалирующей частью официальных изданий, отмечающих каждый год после государственного переворота в мае 1934 года и в своих названиях демонстрирующих радикальность разрыва с близким прошлым, предстоящим 1934 году: «Pirmais gads/Первый год: 1934.15.V - 1935.15.V» и т.д. до «Пятого года», увидевшего свет в 1939 году. Каждый из этих сборников включал раздел «Соответствующий год в зеркале речей государственных мужей». «Первый год» ${ }^{8}$ содержал 25 речей К. Улманиса из 56 опубликованных устных выступлений государственных деятелей; «Второй год» ${ }^{9}$ включал 47 речей, 20 из которых принадлежали К. Улманису. Соотношение между речами главы Правительства и страны (с апреля 1936 года К. Улманис является также Президентом государства) и речами других лиц в сборнике «Третий год» составляло $20: 31^{10}$. В издании «Четвертый год» оно равнялось 25:54 ${ }^{11}$, и, наконец, в сборник «Пятый год» входила 21 речь К. Улманиса при общем рекордном (85) количестве изданных речей ${ }^{12}$.

В-третьих, речи К. Улманиса публиковались в сборниках, предназначенных для использования в основной (шестилетней) школе. Так, например, в 1938 году пятым изданием вышла составленная Янисом Лапиньшем и впервые опубликованная в 1936 году книга «Kārlis Ulmanis jaunatnei/Карлис Улманис молодёжи» ${ }^{13}$. Она включала в себя избранные статьи и фрагменты из 30 речей Президента, причем некоторым текстам для лучшего их усвоения учащимися была придана стихотворная форма ${ }^{14}$.

В-четвертых, без публикаций речей К. Улманиса не обходились специальные тома, выходившие под эгидой Министерства образования и подготовленные Отделом учебных пособий в качестве дара Правительства выпускникам школ разного уровня. Тиражи этих изданий были впечатляющими для Первой Латвийской республики: к примеру, книга

7 Idem, Uguns šķīsta zeltu, grūtības - cilvēku: Valsts Prezidenta K. Ulmaña vēstījums tautai, Rīga 1939.

${ }^{8}$ Pirmais gads $193415 \mathrm{~V}-193515 \mathrm{~V}$, Rīga 1935.

9 Otrais gads $193515 \mathrm{~V}-193615 \mathrm{~V}$, Rīga 1936.

${ }_{10}$ Trešais gads $193615 \mathrm{~V}-193715 \mathrm{~V}$, Rīga 1937.

${ }^{11}$ Ceturtais gads $193715 \mathrm{~V}-193815 \mathrm{~V}$, Rīga 1938.

12 Piektais gads 192815 V-1939 15 V, Rīga 1939.

${ }^{13}$ Kärlis Ulmanis jaunatnei, Rīga 1938.

${ }_{14}$ См., например, K. Ulmanis, Zem Latvijas karoga, Kārlis Ulmanis Jaunatnei, Rīga 1938 , c. $13-15$. 
«Tēvzemei un brīvībai/Отечеству и свободе», адресованная выпускникам основной школы, имела тираж 15590 экземпляров ${ }^{15}$. Далее следует упомянуть издание типа «Мысли мудрых людей». К таковым относится, например, сборник «Degsme/Горение», состоящий из суждений, указаний, призывов и пожеланий К. Улманиса, подобранных Лигонисом (Degsme 1938) ${ }^{16}$. И наконец, в 1939 году вышел в свет первый том из задуманного собрания сочинений (речей и статей) К. Улманиса, включающий в себя тексты 1918-1919 годов ${ }^{17}$. В 1940 же году был выпущен пятый том, охватывающий материалы 1934-1936 годов, поскольку, по словам его составителя Яниса Рудумса, речи именно этого периода сохранились в стенограммах, а также в наметках и черновиках К. Улманиса, и потому их легче было подготовить к публикации ${ }^{18}$. В указанном издании речи расположены в хронологической последовательности, но при этом текст книги никак не структурирован - не выделены разделы (даже по годам), не указаны время и место произнесения речей. Хотя соответствующие комментарии даны в конце тома, но пользование ими весьма затруднено объемом книги в 700 страниц. Такая форма подачи материала «снимает» временной, ситуативный характер речей К. Улманиса, придает им надвременный, абсолютный статус и таким образом прокладывает путь к отождествлению К. Улманиса и Латвии, Улманиса и времени существования Первой Латвийской республики. При этом время предстает как вечность, как неизменное настоящее, в котором растворено прошлое, воплощенное в речах К. Улманиса. Однако начало широкой публикации его речей относится к 1934/35 году - в официальном дискурсе «Первому году», открывшем новую историческую эпоху, суть которой выразил К. Улманис как глава Правительства в своем обращении по радио к народу: «На сей раз народ обрел самого себя. Мы снова (подчеркнуто нами - Т.К.) едины - сыновья и дочери одной земли» (18 мая 1934 года $)^{19}$. Обратим внимание на слово «снова», весьма частотное в лексиконе К. Улманиса и указывающее на возвращение к некоему изначальному состоянию в неопределенном

5 A. Grīns un A. Zālīis, Tēvzemei un brīvībai, Rīga 1937.

K. Ulmanis, Degsme, Rīga 1938.

7 Idem, Runas un raksti, t. 1, Rīga MCMIXL.

18 Ibidem, t. 5, c. 657.

19 K. Ulmanis, Tauta ieguva pati sevi, [in:] idem, Sabiedriskie raksti un runa, Rīga 1935, t. 2 , c. 167. 
прошлом, что абсолютизирует это прошлое, представляя его в качестве парадигмы «нашего существования» сейчас и здесь.

В 1934/35 годах вышло двухтомное собрание сочинений К. Улманиса «Sabiedriskie raksti un runas/Общественные статьи и речи», подготовленное к печати, как заявлено в титулах книг, Юлием Друвой (главный редактор газеты «Brīvā Zeme/Свободная земля»), но на самом деле - скомпрометировавшим свое имя журналистом, ставшим сотрудником «Brīvā Zeme» и часто печатавшимся в этой газете под разными фамилиями или без них. По его словам, сохраненным Жанисом Унамсом в своих воспоминаниях, написанных в эмиграции, он получил от К. Улманиса благодарственное письмо за проделанную работу ${ }^{20}$. Следует заметить, что сам факт публикации речей государственного деятеля является средством его мифологизации. Ибо слово, будучи запечатленным на бумаге и тиражируемым (в чем сказывается архаико-мифическое соединение слова и действия), утверждается в своем миросозидательном значении, а лицо, произнесшее его, предстает в качестве демиурга.

Косвенным подтверждением того служит цель составителя сборника речей К. Улманиса. Она такова: «Отобрать только те речи, которые характеризуют борьбу К. Улманиса за латышскую Латвию, за единый народ и сильную национальную государственную власть» ${ }^{21}$. Такая декларируемая публикатором цель проявляет и задает образ выпрямленного, линейно-одномерного, целенаправленного исторического процесса, творцом которого является К. Улманис. Это в свою очередь указывает на формируемую таким образом квазирелигиозную, квазихристианскую картину мира.

Второй том «Общественных статей и речей» содержит речи, относящиеся к 1917 году (1), к 1918 (1), к 1919 (4), к 1920 (1), к 1925 (2), к 1934 (56) и к 1935 до 22 августа включительно (25). Подобный отбор подчеркивает длительность пути и качественную неравноценность отдельных его звеньев, создает временную перспективу, имеющую место быть благодаря К. Улманису, его слову, которое не просто пронизывает время, а структурирует его, расставляет в нем вехи и определяет иерархию потенциальных событий. В равной мере как и весьма подробная

20 Ž. Unams, Laiku atspulgā, Oldenburga 1953, c. 18-19.

${ }^{21}$ K. Ulmanis, Sabiedriskie raksti, t. 2, c. 3. 
фиксация ситуаций, в которых прозвучала речь, места, аудитории акцентирует тотальность присутствия К. Улманиса в социуме.

Выход в свет двухтомного собрания сочинений К. Улманиса в 1934/35 годах после государственного переворота свидетельствует о придании этим текстам статуса идеологического основания общества, подчеркивает мироустроительный смысл слова К. Улманиса. При этом мироустроение самим К. Улманисом декларировалось как перевоспитание народа. Так, на собрании работников печати, состоявшемся 29 октября 1934 года, он заявил, что предстоит большая работа: «Весь наш народ надо перевоспитать» ${ }^{22}$. Перевоспитание же предполагало изменение мышления людей. Одним из элементов этого нового мышления была внедряемая в сознание аудитории модель прошлого, равно как и модель отношения к нему, которые формируются не только прямыми характеристиками разной глубины прошлого, содержащимися в речах К. Улманиса, но и структурой метатекста - в частности, сборника речей, изданного в составе двухтомника, а также контекстом употребления понятия „история». Именно это и будет основным предметом анализа в данной работе.

Заметим, что факт публикации речи фиксирует момент превращения некоего настоящего (ситуативный контекст речи) в прошлое и введение его в новое настоящее в качестве «инструмента» и материала построения настоящего и будущего. Таким образом, опубликованный текст «стягивает» времена, ибо с момента его издания и распространения он становится частью любого будущего настоящего.

Том речей К. Улманиса содержит 93 текста, 69 из которых относятся ко времени после 15 мая 1934 года, что неявно, но тем не менее реально закладывает представление о наибольшей значимости настоящего и о предшествующем периоде лишь как о подготовительном, т.е. не обладающем качественной определенностью и целостностью, а значит - и самоценностью.

Все подобранные в указанное издание речи разделены на три части. Символическое же и весьма архаическое по происхождению значение числа «три» состоит в указании на восстановленное и дифференцированное единстве. В силу разделенности это единство обладает потенцией динамики, а в силу восстановленности содержит возможность возвращения, что актуализует прошлое, вводит его в «плоть» настоя-

${ }_{22}$ Idem, Preses uzdevumi, [in:] idem, Sabiedriskie raksti, t. 2, c. 303. 
щего в качестве основы, задающей характер движения к будущему. Само же движение оказывается не развитием, а развертыванием однажды возникшего. Это развертывание может быть прервано, но вектор его остается неизменным.

Все три раздела книги имеют особым образом оформленные названия. Крупным шрифтом выделено: «Runas par - /Речи o-», затем следует ненормативное тире и далее - краткая характеристика содержания речей данного периода. Например:

«Runas par - latviešu tautas

brīvības cīņām un

šo cinnu varoņiem/

Речи об - освободительной

борьбе латышского

народа и её героях».

Ненормативная постановка знака препинания уравнивает в своем значении акт речи и её содержание. Более того, приоритет отдается именно акту речи, на что указывает избранный для написания самого слова «runas/речи» особо крупный шрифт. Таким образом манифестируется демиургический характер звучащего слова и формируется представление о том, что именно оно определяет содержание исторического процесса. Правда, это справедливо лишь в отношении слова «вождя и объединителя латышского народа» К. Улманиса. Исключительная роль его слова подчеркивается наличием эпиграфов к каждому разделу рассматриваемого сборника. Они представляют выдержку из какого либо высказывания самого К. Улманиса, что позиционирует его как творца миросдания, а его слова как тотально-всеобъемлющего. Наличие подобных эпиграфов изобличает невостребованность диалога с «другими» и задает представление об унифицированном мире, в котором исключается множественное разнообразие.

Семантически значимыми являются названия разделов данного тома речей К. Улманиса: первого - «Речи об - освободительной борьбе латышского народа и её героях»; второго - «Речи о - необходимости единого народа и сильной латышской государственной власти» и третьего - «Речи о - близких и далеких целях латышского народа, значении 15 мая, деятельности национального Правительства». Они формируют представление о процессе с однозначным содержанием, которое есть борьба за свободу. Целью же её становится единство народа и сильная, этнически чистая государственная власть. Причем, 
поскольку в оформлении разделов не фиксируется временной период, постольку освободительная борьба латышского народа лишается конкретного начала и оказывается исчерпывающей все содержание исторического процесса как в темпорально-неопределенном прошлом, так и в столь же безграничном будущем, на которое указывают «далекие цели национального Правительства». Субъектом борьбы признается латышский народ, извечное существование которого неявно утверждается отсутствием указания на временные границы каждого раздела. Названия разделов говорят также о понимании исторического процесса как направленного, телеологического, линейного, определяемого людьми, обладающими властными позициями (поэтому подчеркнута деятельность национального Правительства). Прошлое при этом выпрямляется, «вычищается» до признания присутствия в нем лишь этнически однородной общности - латышского народа, единодушного в своих мечтаниях и устремлениях к свободе.

Содержательными являются также принципы отбора и распределения публикуемых речей. Первый раздел включает 9 речей, относящихся ко времени с апреля 1917 года по август 1925 года; второй содержит 15 речей, охватывающих период с июня 1921 года по март 1934 года, третий же раздел состоит из 69 речей, произнесенных с мая 1934 и до августа 1935 года. Таким образом, очевидны провалы на «линии времени», что закладывает в сознание читателя представление о дискретности исторического процесса и о неравной значимости его периодов, более того, об оппозиции изначальной и возрождаемой полноты и пустоты, каковой является непосредственно близкое прошлое. Отсюда вытекает оценочно-ценностное отношение к истории, т.е. жизни людей во времени, прошлом и настоящем. Близкое прошлое окрашено негативно, отдаленное, причем разной степени отдаленности, прошлое безусловно позитивно.

Границей разделов рассматриваемого тома речей К. Улманиса дважды предстает его выступление у могилы Зигфрида Мейеровица, первого министра иностранных дел Латвийской республики, товарища К. Улманиса по партии (Латышский крестьянский союз), погибшего в автокатастрофе в августе 1925 года. Первый раздел книги заканчивается речью К. Улманиса, произнесенной от имени Латышского крестьянского союза на похоронах 3. Мейеровица 27 августа 1925 года. Завершением же третьего раздела является речь К. Улманиса у могилы 3. Мейеровица в день десятой годовщины со дня его смерти 22 авгу- 
ста 1935 года. Особая значимость места погребения 3. Мейровица как места коллективного «вос/напоминания», выраженная устно/печатным словом одного и того же лица, отмечает возвращение (и возрождение) к животворящему первоначалу. Суть этого возвращения состоит в соблюдении и следовании явленному и потому заданному образцу жизненного поведения человека. Так, К. Улманис в речи 1935 года подчеркнул: «Пусть, уходя отсюда, мы укрепимся в своей решимости следовать примеру и образцу 3. Мейеровица и быть в своей государственной работе деятельными и порядочными, а также пламенными и неотступными в борьбе - в борьбе до конца за народное благополучие и безопасное и блестящее будущее народа и государства. Так мы лучше всего исполним свой долг, лучше всего послужим выполнению своей задачи - всем строить и укреплять свое государство с несокрушимой верой в солнечную жизнь народа и государства, верой, с какой жил и работал до последнего вздоха незабываемый Зигфрид Мейеровиц» ${ }^{23}$. Выделение места памяти 3. Мейеровица в качестве критерия периодизации истории умаляет значение политической жизни в Латвийской республике, не обнаруживает в ней крупных событий и тем самым в определенной степени «снимает» политическую составляющую исторического процесса. Его содержанием становится не столько политические действия, т.е. различного характера коммуникация разнородных социальных сил, сколько следование однажды данному образцу, которое должно привести к единству и единомыслию, создающих и гарантирующих «блестящее будущее народа и государства». Таким образом выпячивается внутреннее, субъективное содержание исторического процесса, его эмоциональная составляющая. Прошлое при этом приобретает значение «прокрустова ложа», которое позволяет строить благополучное настоящее и будущее.

Однако какой глубины прошлое позиционируется как первоначало? Весьма показательно стремительное углубление прошлого, происшедшее в течение недели, которая разделила два выступления К. Улманиса. Первое состоялась 26 октября 1933 года в Риге на вечере членов Латышского крестьянского союза, второе - 2 ноября 1933 года в Латвийском Сельскохозяйственном Центральном обществе. В первой речи он сказал: «Мы - не без прошлого, не без истории, помогающих нам поставить духовные цели. Наш народ сотни лет (подчеркнуто нами - Т.К.)

${ }^{23}$ Idem, Cīṇā lìdz galam, [in:] idem, Sabiedriskie raksti, t. 2, c. 583-584. 
живет у Балтийского моря, в самом хорошем месте у этого моря, он смог все эти годы продержаться здесь и выстоять в борьбе, происходившей здесь. Это мог только тот народ, у которого была большая внутренняя сила. Разве в будущем будет иначе?» ${ }^{24}$. Через неделю, во втором публичном выступлении К. Улманиса «сотни лет» превратились в тысячи: «Наш народ все время, тысячелетиями был у Балтийского моря, в лучшем месте его восточного побережья, будучи способен завоевать и удержать его (подчеркнуто нами. - Т.К.). Только такой народ, у которого есть большая духовная сила, мог сотни и тысячи лет жить и часто править (подчеркнуто нами. - Т.К.) в столь вожделенной земле. История нам рассказывает об этих бесконечных годах борьбы. Как латыши боролись за эту землю у Балтийского моря! Осажденные врагами, они часто против огромного перевеса сил защищались до последнего, удерживая эту свою землю» ${ }^{25}$. Радикальное углубление прошлого явилось идеологическим средством консолидации латышского сегмента общества Латвии, дающим возможность осознать свою укорененность в мире, а значит укрепится в вере в собственные силы и «солнечное будущее народа и государства». Кроме того, подобное обращение с хронологией, связанное с малоизученностью латышской истории, указывает на воображаемый характер прошлого, а также на функционально-прагматическое отношение к нему.

Обратим внимание на некоторые новые моменты во второй речи К. Улманиса, которые станут основополагающими в его речах 1936-1937 годов. Это, во-первых, признание латышей («нашего народа») в качестве субъекта, способного действовать, а не быть только объектом действия других, о чем говорят такие глагольные формы как «завоевать (iekarot)» и «удержать (noturēt)» вместо «удержаться (noturēties)»; во-вторых, утверждение политической самостоятельности латышей в глубокой древности; в-третьих, констатация непрерывной борьбы, ведущейся «нашим народом», и, в-четвертых, побуждение к гордости, восхищению, эмоциональному воодушевлению как должного отношения к своему прошлому, на что указывает восклицательный знак, венчающий предложение: «Как латыши боролись за эту вожделенную землю возле Балтийского моря!». И наконец, признание окруженности

${ }^{24}$ Idem, Jāmeklē latviešu tautas garīgā misija, [in:] idem, Sabiedriskie raksti, t. 2, c. $67-68$.

${ }^{25}$ Idem, Tauta un valsts, [in:] idem, Sabiedriskie raksti, t. 2, c. 91-92. 
себя врагами - чужеземцами, приходящими отовсюду, общение с которыми возможно лишь в форме борьбы до последнего дыхания. Таким образом, в прошлом исключалось присутствие других, отношения с коими могли бы быть разнообразными и плодотворными. Неприятие других, полное их игнорирование или отождествление с врагами вело не столько к интеллектуальному освоению прошлого, сколько к его присвоению, что отчетливо проявилось, например, в призыве К. Улманиса восстановленный в Елгаве замок называть замком памяти Виестура. В своем выступлении 5 сентября 1937 года в Елгаве на третьем всеобщем Празднике урожая К. Улманис говорил: «Наблюдая и сопереживая древним событиям на сцене, мы чувствуем себя такими близкими и все-таки такими далекими от них, ибо нет никакой видимой связи с этими древними временами. У нас нет ни одного наглядного большого предмета, который бы напомнил нам древние времена, времена борьбы и наших героев тех времен.

Во мне горит желание эти древние времена опять приблизить к нам, оживить, укрепить связи с ними. Это мы можем сделать, предоставив героям древних времен какой-нибудь дар, создав для них хороший знак памяти, перебросив мост назад к древним временам. Так мы почтим их, и сами станем сильнее, ибо почувствуем, что начала нашей жизни глубоки и тянутся далеко в прошлое нашей собственной земли [...]. Этот замок (Елгавский) до сих пор не нашел еще настоящей связи с нашей землей. Он еще не заключен глубоко в нашем сердце, хотя мы сейчас его обживаем. Этот замок строился частями в разное время. Окончен он не был никогда, и только мы сейчас закончим его [...] после того, как в 1919 году поджигатели оставили нам лишь руины. Этот замок принадлежит и будет принадлежать нам, его настоящим строителям. Этот замок ждет, чтобы мы дали ему имя, которое окажет честь самому замку и будет горделивым по отношению к нам. Этого мы достигнем лучше всего, если мы, давая имя, перебросим новый мост назад к нашему прошлому и древности, мост, который соединит дни и труды наших предков с нашими днями и трудами [...] Поэтому я сегодня могу здесь всем сообщить, что решено, начиная с этого дня, наш замок в Елгаве, древней столице Земгале и Курземе [...] называть $[\ldots]$ Замком памяти Виестура» ${ }^{26}$.

${ }^{26}$ Idem, Lauku dzīves standarts mums jāpaceḷ uz augšu, [in:] Ceturtais gads, c. 231-232. 
Таким образом, выявленные параметры образа прошлого и отношения к нему, для которого характерны отказ от осмысления, оценочность, утилитарность, говорят об «аисторичности» повышенного интереса к истории, т.е. прошлого, актуализированного в речах К. Улманиса, и указывают на мифологическую составляющую формируемого данными текстами исторического сознания. О том же свидетельствует и контекст употребления понятия «история», весьма частотного в речах К. Улманиса. Так, 29 речей из 93 опубликованных в «Общественных статьях и речах» содержат термин «история» и его производные (исторический, историк), упоминающиеся 107 раз, причем 92 упоминания встречаются в речах, относящихся ко времени после государственного переворота в мае 1934 года.

Употребление понятия «история» говорит о том, что, во-первых, история предстает хронологически размеченным, структурированным пространством значимости с возможно меняющимися фигурами, ценность которых определяется их причастностью к этому пространству. Само пребывание в этой структурно, но не содержательно законченной картине удостоверяет факт существования нового персонажа, каковым является народ и государство. Ссылка на историю в таком случае становится средством преодоления локальной ограниченности, своеобразной «социализации» латышей, вводимых в контекст потенциально множественного человечества, вне которого экзистенция частного не имеет значения, и потому его существование неполноценно (неисторично). Подобный вывод подтверждается, например, речью К. Улманиса 12 ноября 1919 года на заседании Народного Совета, где он, говоря о военных успехах правительственных сил, подчеркнул: «Мы добились успехов и победы благодаря самоотверженному героизму и способности наших военных сил к самопожертвованию, невиданных еще в истории» ${ }^{27}$; или же речью, прозвучавшей 9 сентября 1934 года на выставке в Лиепае: «В истории немного таких народов, кто так долго мог прожить на одном месте и выстоять против всех бурь и гроз» ${ }^{28}$. При этом знание исторических реалий неважно, существенен сам факт сопоставления. «История», лишенная конкретного содержания, оказывается символи-

${ }^{27}$ Idem, Uzvar, kas cīnās par taisnu un svètu lietu, [in:] idem, Sabiedriskie raksti, t. 2, c. 27.

${ }^{28}$ Idem, Zemnieks ir mūsu visstiprākais pamats, [in:] idem, Sabiedriskie raksti, t. 2, c. 280 . 
ческим обозначением большого Другого, соотнесенность с которым конституирует данную новую социально-политическую общность, дает ей возможность идентифицировать себя и одновременно выполняет психотерапевтическую функцию - питает чувства гордости, достоинства, укорененности в мире.

Во-вторых, история предстает как существование народов и государств, составными частями которого являются прошлое, настоящее и будущее (т.е. история отнюдь не есть лишь прошлое). При этом оно противополагается несуществованию, т.е. неподлинному бытию, неистории. Так, в своей академической речи в Латвийском университете 14 ноября 1934 года по случаю присуждения ему почетной степени доктора агрономии и экономических наук К. Улманис сказал: «Сельское хозяйство - это основа культуры человечества, и об истории какоголибо народа с полным правом мы можем говорить только с того момента, когда этот народ оставляет образ жизни кочевников, поселяется на постоянную жизнь в каком-нибудь определенном месте и в связи с этим создает прочную основу для своей материальной жизни - сельское хозяйство» ${ }^{29}$.

Таким образом, безусловными признаками значимого социального существования, могущего быть названным историей, является оседлая форма жизни, для которой характерны сращенность с землей, постоянство пребывания на одной и той же территории и соответствующий род занятий - сельское хозяйство. Так задается преимущественно пространственное измерение истории - существование народа и государства, но при этом акцентируется не расширение своего пространства, а сохранение наличного, данного от века и его обустройство (показательна характеристика времени после 15 мая 1934 года как периода строительства) $)^{30}$.

В-третьих, употребление понятия «история» в речах К. Улманиса указывает на абсолютизацию и персонификацию существования. История наделяется чертами субъекта, в частности - способностью предъявлять требования: «Будем помнить, что история во все времена потребует от нас ответственности за все наши дела, за все, что мы

${ }^{29}$ Idem, Lauksaimniecības ekonomiskā un politiskā nozīme, [in:] idem, Sabiedriskie raksti, t. 2, c. 323 .

${ }^{30}$ См., например, K. Ulmanis, Mums visiem jāstrādā vairāk nekā citiem, mūsu darbam jābūt dziļăkam, ja gribam kļūt uzvarētāji, [in:] Piektais gads, c. 324. «Время, в которое сейчас живем в обновленной Латвии, заслужило название эпохи строительства». 
делали» ${ }^{31}$; давать свидетельства: «События истории дадут вам свидетельства того, что мы никогда не теряли своего боевого духа» ${ }^{32}$; учить, напоминать, налагать обязанности: «Наша старая и сегодняшняя история учит нас, напоминает и налагает на нас священную обязанность и в нашей личной жизни руководствоваться одним правилом, а именно, справляться с трудностями - это означает побеждать $)^{33}$.Оборотной стороной такого представления об истории является представление о человеке как, главным образом, объекте, подопечном некоей внешней силы, что в конечном итоге ведет к инфантилизации человека.

Абсолютизации и персонификации истории как социальноорганического существования (отсюда упоминание истории в одном ряду с кровью: «Народ - это идея об общей крови, общей земле, общих обычаях, общей истории, общей чести» ${ }^{34}$ ) сопутствует «субстантивирование» того, что субстанцией не обладает, например, таких состояний как независимость, свобода. Подтверждение тому находим в следующих высказываниях К. Улманиса: «...Мы достигли нашей независимости благодаря стремлению народа к государству...» $»^{35}$; «Готов согласиться, что в предыстории нашей свободы большая роль в укреплении наших обстоятельств принадлежала тому факту, что народ был настроен определенно демократически» ${ }^{36}$. Подобная ментальная установка проявляет умаление значимости индивидуального «я», заметное игнорирование человека как субъекта, ибо он значим лишь в качестве органической составляющей народа ${ }^{37}$. Кроме того, абсолютизация и персонификация существования народа и государства влечет за собой неразличение истории как пространственно-временной длительности людских общностей и нарратива о ней. Так, выступая 13 августа 1934 года на курсах учителей истории, К. Улманис в конце своей весьма длинной речи подчеркнул: «Я вначале сказал, что страницы истории учат нас, каково наше прошлое, учит, что мы можем с гордостью смотреть на

${ }^{31}$ Idem, Uzvar tikai drosme, [in:] idem, Sabiedriskie raksti, t. 2, c. 351.

${ }^{32}$ Idem, Pagriež seju pret sauli: Bērzmuižas skolā mācības gadu slēdzot, [in:] idem, Sabiedriskie raksti, t. 2, c. 533 .

${ }^{33}$ Ibidem, c. 537.

${ }^{34}$ K. Ulmanis, Valdības idejas, [in:] idem, Sabiedriskie raksti, t. 2, c. 214.

${ }^{35}$ Idem, Jāgroza Latvijas vēsture, [in:] idem, Sabiedriskie raksti, t. 2, c. 73.

${ }^{36}$ Ibidem, c. 82.

${ }^{37}$ См.: Т. Кузнецова, Речи Карлиса Улманиса как средство формирования культурной памяти (Латвия 1934-1940 г2.), „Acta Humanitarica Universitatis Saulensis, Mokslo darbai", t. 9, Šiauliai 2009, c. 93. 
него ${ }^{38}$. Определенное отождествление жизненной реальности и её текстовой репрезентации отмечает одномерно плоское мировидение, неощущение/непонимание мира как непрерывного, разного характера и на разных уровнях происходящего взаимодействия индивидов, групп, обществ и природы, вещей.

Такая ментальная структура (тождество жизненной реальности и нарратива) выявляет размытость научно-логического мышления, более того, «отрицает» историю как науку (исследование неизвестного). Неслучайно, что К. Улманис в своих речах не говорил об этой грани истории. Напротив, он предлагал «прокрустово ложе» для того, что должно быть обнаружено историческими изысканиями, задавал их искомый результат, причем как бесспорную данность, не подлежащую верификации. И это - события (великие деяния), герои, непрерывная борьба латышского народа за государственность, свободу и честь; любовь к отечеству ${ }^{39}$. Таким образом насаждалась «обратная перспектива» в обращении к прошлому, формирующая само прошлое ${ }^{40}$. Очевидно, что подобное представление об истории, подход к её изучению исключает целостность и качественную определенность исторического процесса.

Понятная в условиях создания самостоятельной государственности тенденция к мифологизации исторического сознания, в частности, к укоренению в сознании аудитории воображаемого прошлого - во временной перспективе оказывается фактором, затрудняющим становление и развитие исторической науки, поскольку содействует смешению политического и научного дискурсов.

\section{Przeszłość w wypowiedziach Kārlisa Ulmanisa (streszczenie)}

Kārlis Ulmanis jest kluczową postacią w historii państwa łotewskiego. Z jego nazwiskiem jest związane powstanie i ewolucja łotewskiej państwowości. Celem

${ }^{38}$ K. Ulmanis, Klausaties vēstures solos, [in:] idem, Sabiedriskie raksti, t. 2, c. 258.

${ }_{39}$ См., например: K. Ulmanis, Latvisku saturu Latvijai, [in:] idem, Sabiedriskie raksti, t. 2, c. 227; idem, Izzudis viss svešais, kas apsedza tautas dzidro un cēlo dvēseli, [in:] Otrais gads, c. 184.

${ }^{40}$ См., например: «Чем больше то, что было, соответствует тому, что есть сейчас, тем будет лучше» - idem, Latviešu tautai ir bijis savs uzdevums un misija, tādi vingai ir arī tagad un būs arī uz priekšu, [in:] Trešais gads, c. 155. 
niniejszego artykułu jest zdefiniowanie niektórych funkcji modelu przeszłości stworzonego w wypowiedziach K. Ulmanisa wygłoszonych po zamachu stanu (15 maja 1934 r.). Strukturalna i semantyczna analiza źródeł historycznych ujawnia takie funkcje „obrazu” przeszłości jako samouznanie Łotyszy, którzy są w stanie działać niezależnie; dochodzenie politycznej niezależności Łotyszy od zarania dziejów; twierdzenie o ciągłej walce Łotyszy o ziemię; uznanie obcych za jedynego wroga. Stosunek do przeszłości, ukształtowany przez wypowiedzi K. Ulmanisa, charakteryzuje się odmową jego zrozumienia, oceny i użyteczności. Takie cechy modelu przeszłości, jak również tryb postawy wobec niego ujawniają mitologiczny składnik świadomości historycznej, uformowany przez wypowiedzi K. Ulmanisa.

\section{The past in the Kārlis Ulmanis' speeches (summary)}

Kārlis Ulmanis is the key historical person of Latvian state. The formation and evolution of Latvian statehood was connected with his name. The aim of this article is to define some features of the model of the past formed by K. Ulmanis' speeches delivered after the coup d'etat (15 May, 1934). The structural and semantic analysis of historical sources reveals such features of the "image" of the past as the recognition of Letts as themselves who are able to act independently; assertion of Letts' political independence from extreme antiquity; ascertaining the Letts' constant struggle for their land; acknowledgment of the strangers as the only enemy. The attitude towards the past formed by K. Ulmanis' speeches is characterized by refusal from its comprehension, evaluation and utility. Such features of the model of the past as well as mode of the attitude towards it reveal a mythological component of the historical consciousness formed by K. Ulmanis' speeches. 